\title{
The relevance of the IgG subclass of autoantibodies for blister induction in autoimmune bullous skin diseases
}

\author{
Cassian Sitaru • Sidonia Mihai · Detlef Zillikens
}

Received: 13 November 2006 / Revised: 20 December 2006 / Accepted: 8 January 2007 / Published online: 3 February 2007

(C) Springer-Verlag 2007

\begin{abstract}
Autoimmune bullous skin diseases are characterized by autoantibodies and $\mathrm{T}$ cells specific to structural proteins maintaining cell-cell and cellmatrix adhesion in the skin. Existing clinical and experimental evidence generally supports a pathogenic role of autoantibodies for blister formation. These autoantibodies belong to several IgG subclasses, which associate with different functional properties and may thus determine the pathogenic potential of $\mathrm{IgG}$ antibodies. In pemphigus diseases, binding of IgG to keratinocytes is sufficient to cause intraepidermal blisters without engaging innate immune effectors and IgG4 autoantibodies seem to mainly mediate acantholysis. In contrast, in most subepidermal autoimmune blistering diseases, complement activation and recruitment and activation of leukocytes by autoantibodies are required for blister induction. In these conditions, tissue damage is thought to be mainly mediated by $\operatorname{IgG} 1$, but not IgG4 autoantibodies. This review summarizes the current knowledge on the pathogenic relevance of the IgG subclass of autoantibodies for blister formation. Characterization of the pathogenically relevant subclass(es) of autoantibodies not only provides mechanistic insights, but should greatly facilitate the development of improved therapeutic modalities of autoimmune blistering diseases.
\end{abstract}

Keywords Autoimmune bullous diseases $\cdot \operatorname{IgG}$ subclasses $\cdot$ Complement

C. Sitaru $(\triangle) \cdot$ S. Mihai $\cdot$ D. Zillikens

Department of Dermatology, University of Lübeck,

Ratzeburger Allee 160, 23538 Lübeck, Germany

e-mail: csitaru@fastmail.fm

\section{Introduction}

Autoimmune blistering diseases are associated with an autoimmune response directed to structural proteins mediating cell-cell and cell-matrix adhesion in the skin $[62,66]$. Both autoantibodies and autoreactive $\mathrm{T}$ cells have been found in patients with these organ-specific autoimmune diseases. However, blister induction is mainly mediated by autoantibodies. Autoimmune blistering diseases are classified based on the ultrastructural site of deposition of immunoreactants and on the molecular target of autoantibodies. Diseases of the pemphigus group are associated with autoantibodies to epidermal components mediating cell-cell adhesion and are characterized by acantholytic blisters within the epidermis [39, 71]. Tissue-bound and circulating autoantibodies to the dermal-epidermal junction are characteristic immunopathological features of subepidermal autoimmune bullous diseases [62, 85]. Target antigens of autoantibodies have been identified for the majority of autoimmune blistering diseases. In most of these diseases, the pathogenicity of autoantibodies is supported by clinical observations and extensive experimental evidence [62].

Antibodies are effector molecules of the adaptive immune system secreted by plasmablasts and longlived plasma cells. Antibody responses are physiologically mounted following an infection or vaccination and protect against various pathogens. Occasionally, in the setting of an autoimmune disease, antibodies to autologous structures may develop and cause different forms of tissue damage. The immunopathology induced by autoantibodies, similar to the immunity mediated by antibodies to pathogens, relies on several mechanisms of action of antibodies, including direct 
mechanisms, which are mediated by the antibody's variable regions (e.g., by steric hindrance and signal transduction), and indirect mechanisms, which are triggered by the constant regions of antibodies. For the latter, (auto)antibodies typically interact through their Fc portions with other factors of the innate immune system, including the complement system and inflammatory cells [62].

Antibodies of the $\mathrm{IgG}$ isotype predominate in the systemic immune response, as reflected in serum immunoglobulin concentration, and activate a wide range of effector functions. Four subclasses of $\mathrm{IgG}$ are defined, originally from the antigenic uniqueness of their heavy chains, which are products of distinct genes $[20,27,77]$. The subclasses are designated as IgG1, $\mathrm{IgG} 2, \mathrm{IgG} 3$ and $\mathrm{IgG} 4$ in order of their serum concentration $\sim 60,25,10$ and $5 \%$, respectively. Although the heavy chains show $>95 \%$ sequence homology, each IgG subclass expresses a unique profile of effector activities [35, 56, 59, 76, 80, 82]. Protein antigens characteristically provoke $\mathrm{IgG} 1$ and $\mathrm{IgG} 3$ responses and these isotypes are able to activate all types of $\mathrm{Fc}$ receptors and the $\mathrm{C} 1$ component of complement. The IgG4 subclass may be characteristic of chronic antigen stimulation, as in autoimmune disease; it has restricted Fc receptor activating abilities and does not activate $\mathrm{C} 1 \mathrm{q}$. The IgG2 subclass often predominates in responses to carbohydrate antigens; it has restricted Fc receptor and $\mathrm{C} 1$ activating abilities [35, 56, 80, 82].

The pathogenic potential unfolded by autoantibodies is determined not only by their specificity and affinity, but also by their isotype. Autoantibodies against cutaneous proteins in autoimmune blistering diseases belong to different IgG subclasses. This paper summarizes the current knowledge on the relevance of $\mathrm{IgG}$ subclasses for tissue injury in autoimmune bullous diseases.

\section{Pemphigus diseases}

Pemphigus designates a group of life-threatening-autoimmune blistering diseases characterized by intraepithelial blister formation caused by loss of cell-cell adhesion [39, 54, 71]. IgG autoantibodies in patients with pemphigus seem to mediate their pathogenic functions independently of their Fc portions [62]. Patients' IgG autoantibodies are pathogenic in C5-deficient mice and $\mathrm{F}(\mathrm{ab}$ ')2, Fab, and $\mathrm{scFv}$ fragments of autoantibodies induce acantholysis by passive transfer in wild type mice showing that complement activation or other Fc-mediated effects are not required for pathogenicity [4, 21, 45, 55].
Numerous studies clearly demonstrated that tissue bound and circulating autoantibodies in pemphigus patients mainly belong to the $\mathrm{IgG} 1$ and $\mathrm{IgG} 4$ subclasses [2, 5, 8, 9, 16-18, 23, 28, 36, 38, 40, 49, 61, 79]. The IgG subclass distribution of autoantibodies in a representative pemphigus patient is shown in Fig. 1 . While it is generally agreed upon the subclass distribution of IgG autoantibodies, the relevance of autoantibodies of different $\operatorname{IgG}$ isotypes for acantholytic blistering in pemphigus is still a matter of debate. IgG4 autoantibodies, known to have poor complement- and leucocyte-activating properties, predominate in pemphigus vulgaris and foliaceus. While several studies suggest a pathogenic role of IgG4 in pemphigus, the capacity of IgG1 autoantibodies to induce acantholysis has not yet been ruled out. In patients with active pemphigus vulgaris, IgG4 autoantibodies against desmogleins were found to predominate $[5,17,23,40]$. The transplacental transfer of these autoantibodies in mothers with pemphigus induces acantholytic skin disease in neonates [52]. In endemic pemphigus foliaceus the early antibody response in normal subjects living in the endemic area and in patients before the onset of clinical disease is mainly IgG1. Acquisition of an $\mathrm{IgG} 4$ response seems to be a key step in the development of clinical disease [78]. Clinical and experimental data suggests that IgG1 differ from IgG4 autoantibodies in terms of both their epitope specificity and pathogenic potential $[9,42]$. A monoclonal IgG4 antibody against desmoglein 3 generated from a patient with active pemphigus vulgaris induces acantholysis in cultured skin and when injected in neonatal mice [86]. The fact that IgG4 antibodies purified from patients with fogo selvagem, an endemic form of pemphigus foliaceus, are pathogenic in mice further supports the notion that $\mathrm{IgG} 4$ is pathogenic and complement activation is not required for blister formation [57], but does not exclude a pathogenic potential of IgG autoantibodies belonging to other subclasses. Indeed, in several pemphigus foliaceus patients, only IgG1 autoantibodies were found that caused intraepidermal blisters by passive transfer into neonatal mice [29]. This observation clearly shows that autoantibodies of different subclasses may display blister-inducing activity. In addition, in paraneoplastic pemphigus, autoantibodies against desmoglein 3 mainly belong to the $\operatorname{IgG} 1$ and IgG2 subclasses suggesting that the IgG subclass per se is not a direct determinant of the antibodies' pathogenic potential in pemphigus [24].

Experimental evidence using a murine model of pemphigus vulgaris shows that, similar to human pemphigus, the autoimmune response in mice is biased toward non-complement fixing autoantibodies. In this 
Fig. 1 IgG subclass distribution of circulating pemphigus autoantibodies. A 1:10 dilution of serum from a patient with pemphigus foliaceus was incubated with $6 \mu \mathrm{m}$-thick cryostat sections of normal human skin for $30 \mathrm{~min}$ at room temperature. Bound antibodies, visualized using an FITC-labeled antibody specific to human $\mathrm{IgG}$, were of a IgG1 and $\mathbf{d} \mathrm{IgG} 4$ subclasses. In contrast, no binding of $\mathbf{b}$ $\mathrm{IgG} 2$ and $\mathbf{c} \mathrm{IgG} 3$ autoantibodies was evidenced
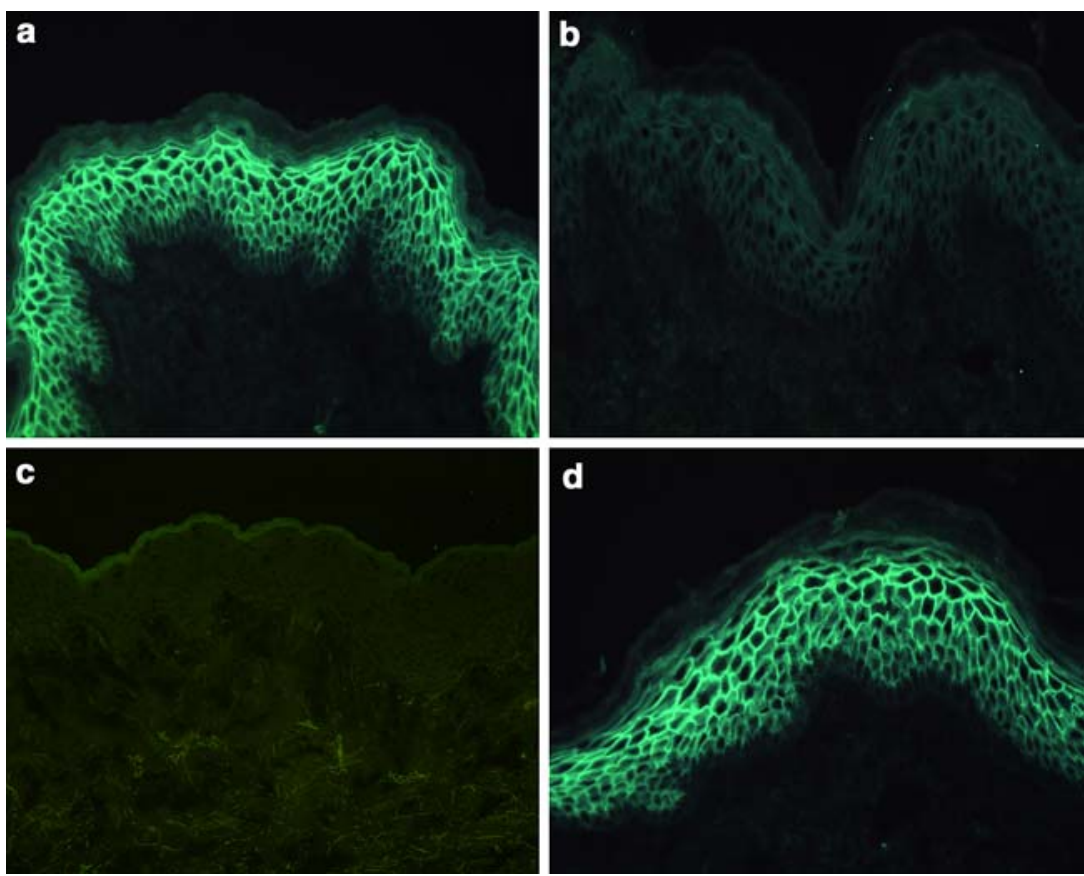

model, in immunodeficient mice infused with splenocytes from desmoglein-deficient mice immunized against this antigen, $\mathrm{IgG}$ autoantibodies are produced by homeostatically expanded antigen-specific B cells under $\mathrm{T}$ cell control and mice develop a phenotype reminiscent of pemphigus vulgaris. These IgG autoantibodies predominantly belong to the IgG1 subclass, which is a non-complement fixing antibody in the mouse $[3,50]$. These results demonstrate that noncomplement-fixing autoantibodies can induce acantholysis and suggest a similar mechanism in patients, but they do not exclude a pathogenic potential of patients' IgG1 autoantibodies in pemphigus.

In conclusion, in pemphigus diseases the autoantibodies mainly belong to the IgG4 and IgG1 subclasses. Extensive experimental evidence demonstrates the blister-inducing potential of IgG4 autoantibodies. The pathogenic activity of autoantibodies of other subclasses seems likely, but needs further investigation.

\section{Subepidermal autoimmune blistering diseases}

Bullous pemphigoid and pemphigoid gestationis

Bullous pemphigoid is an autoimmune blistering disease characterized by subepidermal blisters and associated with linear deposits of $\mathrm{C} 3$ and $\operatorname{IgG}$ at the epidermal basement membrane zone. Autoantibodies in bullous pemphigoid are directed against two hemidesmosomal antigens, BP230 and BP180/type
XVII collagen [87]. Pemphigoid gestationis, also referred to as herpes gestationis, is a subepidermal blistering disease associated with pregnancy and characterized by linear deposition of $\mathrm{C} 3$ and, to a lesser extent of $\mathrm{IgG}$ at the dermal-epidermal junction, as detected by immunofluorescence microscopy $[62,66]$. The autoimmune response in bullous pemphigoid and pemphigoid gestationis is mainly directed against epitopes clustered within the immunodominant 16th non-collagenous (NC16) A region of type XVII collagen [48, 65, 88].

Experimental evidence generally supports the pathogenic role of autoantibodies against type XVII collagen for blister formation. Data from passive transfer animal models strongly suggest that antibodies to type XVII collagen are directly involved in the pathogenesis of bullous pemphigoid [44, 84]. In addition, in an ex vivo model utilizing cryosections of human skin, it has been demonstrated that binding of autoantibodies to the immunodominant NC16A domain of type XVII collagen, is the first critical step in subepidermal blister formation [31, 64].

Analysis of the subclass distribution of $\operatorname{IgG}$ autoantibodies in the skin of patients with bullous pemphigoid by immunofluorescence microscopy, revealed IgG4 as being the predominant subclass of autoantibodies in bullous pemphigoid, followed by IgG1 autoantibodies, while IgG2 and IgG3 autoantibodies were found only occasionally [1, 10-12, 22, 61, 83]. In addition, serum autoantibodies binding to the dermal-epidermal junction by immunofluorescence microscopy also mainly belong to the IgG4 and IgG1 subclasses [10, 11, 61, 83]. 


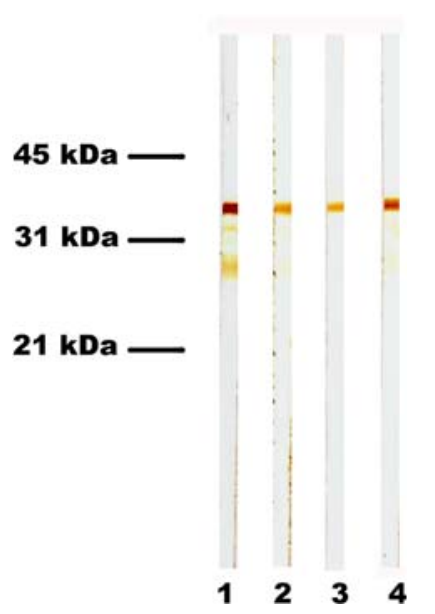

Fig. $2 \mathrm{IgG} 1$ and $\mathrm{IgG} 4$ autoantibodies mainly target type XVII collagen in bullous pemphigoid. Immunoblot analysis of serum from a bullous pemphigoid patient with recombinant type XVII collagen revealed that reactivity against its immunodominant domain consists mainly of IgG1 (lane 1) and IgG4 (lane 4), and less IgG2 (lane 2) and IgG3 (lane 3) autoantibodies

Subsequent molecular analysis of IgG autoantibodies by immunoblotting and ELISA generally confirmed the predominance of $\mathrm{IgG} 1$ and $\mathrm{IgG} 4$ autoantibodies reactive with type XVII collagen and BP230 (Fig. 2) [6, 19, 32, 41, 69].

In contrast to bullous pemphigoid, in pemphigoid gestationis tissue-bound and circulating autoantibodies seem to mainly belong to the $\mathrm{IgG} 1$ and $\mathrm{IgG} 3$ subclasses $[14,37]$. However, a recent study challenged these reports revealing $\mathrm{IgG} 4$ as the predominant IgG subclass of tissue-bound autoantibodies in pemphigoid gestationis patients [53], a pattern similar to the one found in bullous pemphigoid. Further studies should solve this contradiction.

Data from several studies in patients suggested a pathogenic role of IgG1 autoantibodies for blister formation (briefly reviewed in [43]). In a recent study,
ELISA analysis showed that autoantibodies against the $\mathrm{N}$-terminus of the extracellular domain of type XVII collagen predominantly belong to the IgG1 subclass. More importantly, a NC16A-specific IgG1 response was predominant in the acute phase of bullous pemphigoid, while IgG4 was predominantly detected in bullous pemphigoid patients in remission [32]. Using immunoaffinity purified IgG subclasses, it has been shown that IgG1, but not IgG4 autoantibodies from bullous pemphigoid patients activate the complement system in vitro (Fig. 3) [46, 72]. This observation is in line with the currently accepted view that $\mathrm{IgG} 4$ is unable to activate the classical pathway of complement. However, until recently it was unclear which $\mathrm{IgG}$ subclass is actually pathogenic in bullous pemphigoid. Using the ex vivo cryosection model, we demonstrated that, in addition to IgG1, IgG4 autoantibodies are also able to activate leukocytes and to induce leukocytedependent tissue damage (Fig. 4) [46]. Our results are in line with recent studies demonstrating that both polyclonal human IgG1 and IgG4 from patients with Wegener's granulomatosis and chronic urticaria can activate leukocytes $[33,70]$. Although the pathogenic potential of IgG4 autoantibodies was significantly lower compared to IgG1, IgG4 autoantibodies, which generally predominate, may activate the inflammatory cells already recruited into the upper dermis by complement-fixing IgG1 autoantibodies and thus amplify the recruitment of additional leukocytes and the extent of blister formation. Therefore, when associated with IgG1 and/or IgG3 autoantibodies, IgG4 may significantly contribute to the pathology induced by autoantibodies in antibody-induced granulocyte-mediated autoimmune blistering diseases [46].

Several reports suggested that binding of bullous pemphigoid antibodies to keratinocytes triggers a signal transduction [58, 73-75]. Bullous pemphigoid autoantibodies trigger a signal-transducing event that
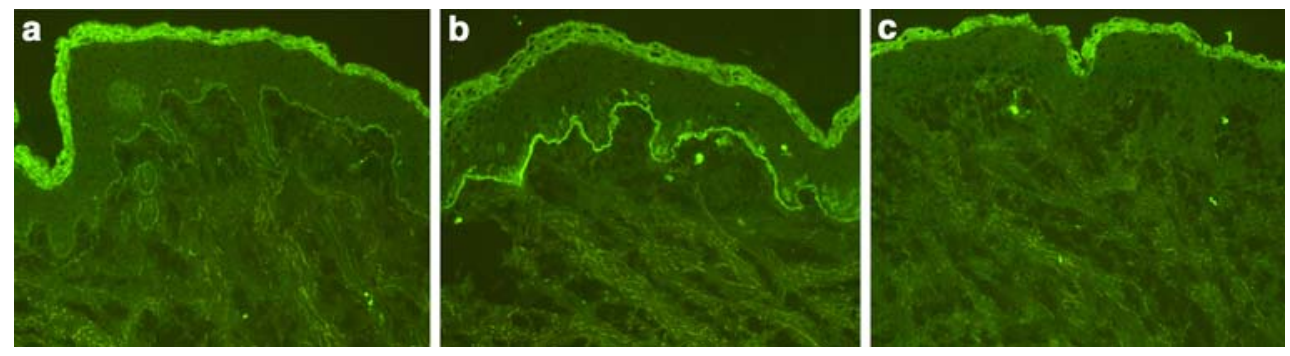

Fig. 3 IgG4 autoantibodies, in contrast to IgG1, do not fix complement to the dermal-epidermal junction in bullous pemphigoid. Cryosections of normal human skin were incubated with serum and immunoaffinity purified IgG1 and IgG4 antibody preparations from a bullous pemphigoid patient and, subsequently, treated with normal human serum as a source of complement.
Both a serum and b purified IgG1 autoantibodies fixed complement $\mathrm{C} 3$ at the dermal-epidermal junction in a linear fashion. $\mathbf{c}$ In contrast, incubation of cryosections with IgG4 specific for the dermal-epidermal junction does not result in $\mathrm{C} 3$ deposition (all magnifications, $\times 200$ ) 

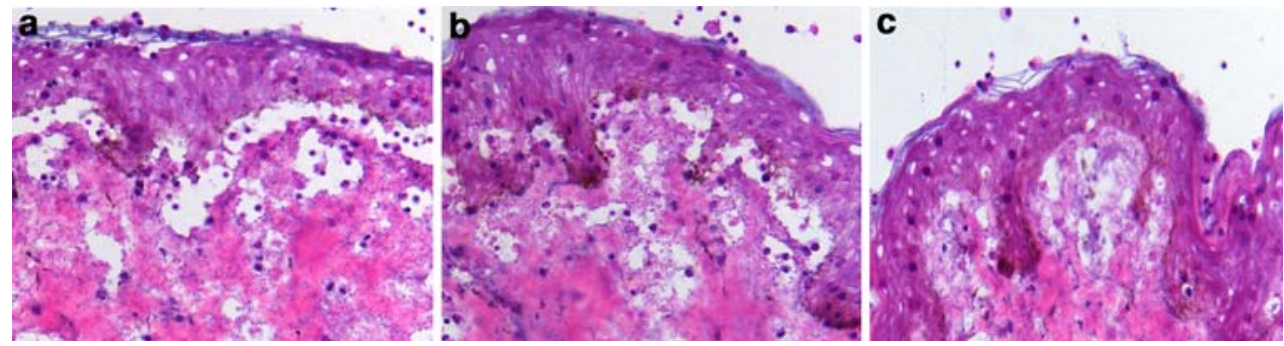

Fig. 4 IgG4 autoantibodies from bullous pemphigoid patients induce dermal-epidermal separation in sections of human skin. Dermal-epidermal separation in sections of normal human skin is induced by a IgG1 and b IgG4 autoantibodies from a bullous

leads to expression and secretion of interleukin- 6 and interleukin-8 from human cultured keratinocytes [58]. A series of studies from another group demonstrated that IgG1 autoantibodies from bullous pemphigoid patients and rabbit IgG against type XVII collagen induces $\mathrm{Ca}^{2+}$ release from intracellular storage sites [73-75]. Interestingly, complement activation by these IgG1 autoantibodies did not result in lysis of keratinocytes [73]. While the relevance of these findings is not yet fully understood, IgG2 and IgG4 patients' autoantibodies were found to inhibit the transient increase of intracellular $\mathrm{Ca}^{2+}$ induced by bullous pemphigoid $\mathrm{IgG} 1$ antibody [74].

\section{Mucous membrane pemphigoid}

Mucous membrane pemphigoid is a heterogeneous disease with regard to the clinical phenotype and the target antigens. Different target antigens have been identified in mucous membrane pemphigoid, including BP180, laminins 5 (epiligrin) and 6, $\beta 4$ integrin $[62,66]$. In general, autoantibodies in mucous membrane pemphigoid mainly belong to the IgG4 and IgG1 subclasses [7, 34]. Interestingly, in anti-epiligrin cicatricial pemphigoid, autoantibodies against laminin 5 almost exclusively belong to the IgG4 subclass [34]. Consistent with these findings, sera from patients with anti-laminin 5 IgG autoantibodies do not fix $\mathrm{C} 3$ to the epidermal basement membranes and do not induce leukocytedependent dermal-epidermal separation in vitro [34, 60]. These data suggest that complement activation does not play a major role in this disease and subepidermal blisters in these patients may develop via a direct effect of anti-laminin $5 \mathrm{IgG}$ itself $[34,60]$.

Diseases associated with autoimmunity against type VII collagen

Epidermolysis bullosa acquisita is a chronic subepidermal blistering disease characterized by circulating and pemphigoid patient. c IgG antibodies from a healthy control (NHS) do not induce subepidermal splits (all magnifications, $\times 200$ )

tissue-bound antibodies targeting the non-collagenous domain 1 (NC1) of type VII collagen. The pathogenic relevance of antibodies against type VII collagen is supported by compelling evidence: (1) autoantibodies from patients with epidermolysis bullosa acquisita were shown to recruit and activate leukocytes ex vivo resulting in dermal-epidermal separation in cryosections of human skin [60, 63], (2) antibodies against type VII collagen induce subepidermal blisters when passively transferred into mice [67, 81], (3) immunization with recombinant autologous type VII collagen induces an autoimmune response to this protein resulting in a blistering phenotype closely resembling human epidermolysis bullosa acquisita [68].

Tissue-bound and circulating antibodies in epidermolysis bullosa acquisita patients mainly belong to the IgG1 and IgG4 subclasses [7, 15, 26, 47]. A similar distribution of $\operatorname{IgG}$ subclasses of autoantibodies is found also in SJL mice immunized against murine type VII collagen [68]. In these mice, while both non-complement-fixing $\mathrm{IgG} 1$ and complement-fixing $\mathrm{IgG} 2 \mathrm{a}$ and $\mathrm{IgG} 2 \mathrm{~b}$ autoantibodies are produced after immunization, $\operatorname{IgG} 2 \mathrm{a} / \mathrm{b}$ autoantibodies seem to induce blistering [68].

Systemic lupus erythematosus and inflammatory bowel diseases may be also associated with autoantibodies against type VII collagen [13, 25, 30, 51]. However, in contrast to epidermolysis bullosa acquisita, autoantibodies from patients with bullous systemic lupus erythematosus and inflammatory bowel diseases mainly belong to $\operatorname{IgG} 2$ and $\operatorname{IgG} 3$, respectively [30, 51]. The pathogenic relevance of autoantibodies against type VII collagen in inflammatory bowel diseases has not yet been addressed [51]. IgG autoantibodies from patients with bullous systemic lupus erythematosus were shown to induce leukocyte-dependent dermalepidermal separation in cryosections of human skin ex vivo [30]. This findings suggest that the presence of complement-fixing autoantibodies is not a strict requirement for blistering in patients. 


\section{Conclusion and perspectives}

The polyclonal antibody response against structural skin proteins in autoimmune bullous diseases is heterogeneous, but shows a skewing in subclass distribution of autoantibodies. The strong bias toward production of IgG4 autoantibodies in these organ-specific autoimmune diseases suggests chronic antigenic stimulation. In pemphigus, IgG4 autoantibodies that dominate the autoimmune response are clearly pathogenic. However, IgG1 autoantibodies also likely possess blister-inducing potential that requires further investigation. In subepidermal autoimmune blistering diseases, the effector functions of autoantibodies are important for blistering. Thus, in bullous pemphigoid and epidermolysis bullosa acquisita, complement-fixing IgG1 autoantibodies may show a significantly higher pathogenic potential when compared with IgG4 autoantibodies. Characterization of the blister-inducing capacity of different subclasses of autoantibodies in autoimmune bullous diseases will not only provide relevant mechanistic insights, but should also greatly facilitate the development of improved therapeutic modalities of autoimmune blistering diseases. Detailed knowledge on the pathogenic IgG isotype(s) will serve as a basis for the development of IgG subclass-specific immunoapheresis, skewing autoantibody production toward non-pathogenic subclasses by immunotherapy or blocking of complement or leukocytes activation by targeting specific IgG subclasses. A promising approach is represented by interventions aimed at inhibiting the production of autoantibodies in general or skewing the production of autoantibodies toward non-pathogenic subclasses. The molecular targets of these approaches may include different cytokines (e.g., IL-12 and IL-17) and their activity could be modulated using inhibitory antibodies, small peptide inhibitors or peptidomimetics as well as immunization with the autoantigen together with adjuvants known to induce a $\mathrm{Th} 2$ immune response.

Acknowledgments This work was supported by grants from the Deutsche Forschungsgemeinschaft (Zi 439/6-2 and SI 1281/1-1) and Else-Kröner-Fresenius-Stiftung (P30-06//A24/06).

\section{References}

1. Al-Karawi KS (2002) Immunoglobulin G subclass distribution of bullous pemphigoid autoantibodies and complement fixation studies. Saudi Med J 23:1492-1495

2. Allen EM, Giudice GJ, Diaz LA (1993) Subclass reactivity of pemphigus foliaceus autoantibodies with recombinant human desmoglein. J Invest Dermatol 100:685-691

3. Amagai M, Tsunoda K, Suzuki H, Nishifuji K, Koyasu S, Nishikawa T (2000) Use of autoantigen-knockout mice in devel- oping an active autoimmune disease model for pemphigus. J Clin Invest 105:625-631

4. Anhalt GJ, Till GO, Diaz LA, Labib RS, Patel HP, Eaglstein NF (1986) Defining the role of complement in experimental pemphigus vulgaris in mice. J Immunol 137:2835-2840

5. Ayatollahi M, Joubeh S, Mortazavi H, Jefferis R, Ghaderi A (2004) IgG4 as the predominant autoantibody in sera from patients with active state of pemphigus vulgaris. J Eur Acad Dermatol Venereol 18:241-242

6. Bernard P, Aucouturier P, Denis F, Bonnetblanc JM (1990) Immunoblot analysis of IgG subclasses of circulating antibodies in bullous pemphigoid. Clin Immunol Immunopathol 54:484-494

7. Bernard P, Prost C, Aucouturier P, Durepaire N, Denis F, Bonnetblanc JM (1991) The subclass distribution of IgG autoantibodies in cicatricial pemphigoid and epidermolysis bullosa acquisita. J Invest Dermatol 97:259-263

8. Bhol K, Mohimen A, Ahmed AR (1994) Correlation of subclasses of IgG with disease activity in pemphigus vulgaris. Dermatology 189:85-89

9. Bhol K, Natarajan K, Nagarwalla N, Mohimen A, Aoki V, Ahmed AR (1995) Correlation of peptide specificity and IgG subclass with pathogenic and non-pathogenic autoantibodies in pemphigus vulgaris: a model for autoimmunity. Proc Natl Acad Sci USA 92:5239-5243

10. Bird P, Friedmann PS, Ling N, Bird AG, Thompson RA (1986) Subclass distribution of IgG autoantibodies in bullous pemphigoid. J Invest Dermatol 86:21-25

11. Brooks WS, Lee YY, Abell E, Deng JS (1989) Comparison of IgG subclasses and complement binding activity of autoantibodies from patients with bullous pemphigoid and pemphigus. J Clin Lab Anal 3:307-311

12. Buschman KE, Seraly M, Thong HY, Deng JS, Draviam RP, Abernethy JL (2002) A predominant IgG4 subclass may be responsible for false-negative direct immunofluorescence in bullous pemphigoid. J Cutan Pathol 29:282-286

13. Chen M, O'Toole EA, Sanghavi J, Mahmud N, Kelleher D, Weir D, Fairley JA, Woodley DT (2002) The epidermolysis bullosa acquisita antigen (type VII collagen) is present in human colon and patients with Crohn's disease have autoantibodies to type VII collagen. J Invest Dermatol 118:1059-1064

14. Chimanovitch I, Schmidt E, Messer G, Dopp R, Partscht K, Bröcker EB, Giudice GJ, Zillikens D (1999) IgG1 and IgG3 are the major immunoglobulin subclasses targeting epitopes within the NC16A domain of BP180 in pemphigoid gestationis. J Invest Dermatol 113:140-142

15. Cho HJ, Lee IJ, Kim SC (1998) Complement-fixing abilities and IgG subclasses of autoantibodies in epidermolysis bullosa acquisita. Yonsei Med J 39:339-344

16. David M, Katzenelson V, Hazaz B, Ben-Chetrit A, Sandbank M (1989) Determination of IgG subclasses in patients with pemphigus with active disease and in remission. Arch Dermatol 125:787-790

17. David M, Katzenelson V, Mimouni D, Milner Y (2006) The distribution of pemphigus vulgaris-IgG subclasses in patients with active disease. J Eur Acad Dermatol Venereol 20:232

18. Dmochowski M, Hashimoto T, Nishikawa T (1992) The analysis of IgG subclasses of anti-intercellular antibodies in pemphigus by an immunoblot technique. Arch Dermatol Res 284:309-311

19. Döpp R, Schmidt E, Chimanovitch I, Leverkus M, Bröcker $\mathrm{EB}$, Zillikens D (2000) IgG4 and IgE are the major immunoglobulins targeting the NC16A domain of BP180 in bullous pemphigoid: serum levels of these immunoglobulins reflect disease activity. J Am Acad Dermatol 42:577-583 
20. Dray S (1960) Three gamma-globulins in normal human serum revealed by monkey precipitins. Science 132:1313-1314

21. Espana A, Diaz LA, Mascaro JM Jr, Giudice GJ, Fairley JA, Till GO, Liu Z (1997) Mechanisms of acantholysis in pemphigus foliaceus. Clin Immunol Immunopathol 85:83-89

22. Flotte TJ, Baird LG (1986) Immunoglobulin light and heavy chain isotypes in skin diseases: restricted distribution in bullous pemphigoid and linear IgA bullous dermatosis. J Immunol 136:491-496

23. Futei Y, Amagai M, Ishii K, Kuroda-Kinoshita K, Ohya K, Nishikawa T (2001) Predominant IgG4 subclass in autoantibodies of pemphigus vulgaris and foliaceus. J Dermatol Sci 26:55-61

24. Futei Y, Amagai M, Hashimoto T, Nishikawa T (2003) Conformational epitope mapping and $\mathrm{IgG}$ subclass distribution of desmoglein 3 in paraneoplastic pemphigus. J Am Acad Dermatol 49:1023-1028

25. Gammon WR, Briggaman RA (1993) Epidermolysis bullosa acquisita and bullous systemic lupus erythematosus. Diseases of autoimmunity to type VII collagen. Dermatol Clin 11:535547

26. Gandhi K, Chen M, Aasi S, Lapiere J-C, Woodley D, Chan LC (2000) Autoantibodies to type VII collagen have heterogenous subclass and light chain compositions and their complement-activating capacitities do not correlate with the inflammatory clinical phenotype. J Clin Immunol 20:416-423

27. Grey HM, Kunkel HG (1964) H-chain subgroups of myeloma proteins and normal 7s-gammaglobulins. J Exp Med 120:253266

28. Hacker MK, Janson M, Fairley JA, Lin MS (2002) Isotypes and antigenic profiles of pemphigus foliaceus and pemphigus vulgaris autoantibodies. Clin Immunol 105:64-74

29. Hacker-Foegen MK, Janson M, Amagai M, Fairley JA, Lin MS (2003) Pathogenicity and epitope characteristics of antidesmoglein-1 from pemphigus foliaceus patients expressing only IgG1 autoantibodies. J Invest Dermatol 121:1373-1378

30. Herrero-Gonzalez JE, Mascaro JM, Herrero C, Dilling A, Zillikens D, Sitaru C (2006a) Autoantibodies from bullous systemic lupus erythematosus patients induce recruitment of leukocytes to the dermal-epidermal junction and subepidermal splits in cryosections of human skin. Arch Dermatol $142: 1-3$

31. Herrero-Gonzalez JE, Brauns O, Egner R, Ronspeck W, Mascaro JM Jr, Jonkman MF, Zillikens D, Sitaru C (2006b) Immunoadsorption against two distinct epitopes on human type XVII collagen abolishes dermal-epidermal separation induced in vitro by autoantibodies from pemphigoid gestationis patients. Eur J Immunol 36:1039-1048

32. Hofmann S, Thoma-Uszynski S, Hunziker T, Bernard P, Koebnick C, Stauber A, Schuler G, Borradori L, Hertl M (2002) Severity and phenotype of bullous pemphigoid relate to autoantibody profile against the $\mathrm{NH}_{2}$ and $\mathrm{COOH}$-terminal regions of the BP180 ectodomain. J Invest Dermatol 119:1065-1073

33. Holland M, Hewins P, Goodall M, Adu D, Jefferis R, Savage CO (2004) Anti-neutrophil cytoplasm antibody IgG subclasses in Wegener's granulomatosis: a possible pathogenic role for the IgG4 subclass. Clin Exp Immunol 138:183-192

34. Hsu R, Lazarova Z, Yee C, Yancey KB (1997) Non-complement fixing, IgG4 autoantibodies predominate in patients with anti-epiligrin cicatricial pemphigoid. J Invest Dermatol 109:557-561

35. Janeway CA, Travers P, Walport M, Shlomchik M (2001) Immunobiology, 5th edn. Garland, New York, pp 360-361

36. Jones CC, Hamilton RG, Jordon RE (1988) Subclass distribution of human IgG autoantibodies in pemphigus. J Clin Immunol 8:43-49
37. Kelly SE, Cerio R, Bhogal BS, Black MM (1989) The distribution of IgG subclasses in pemphigoid gestationis: PG factor is an IgG1 autoantibody. J Invest Dermatol 92:695-698

38. Kim YH, Geoghegan WD, Jordon RE (1990) Pemphigus immunoglobulin $\mathrm{G}$ subclass autoantibodies: studies of reactivity with cultured human keratinocytes. J Lab Clin Med 115:324-331

39. Kottke MD, Delva E, Kowalczyk AP (2006) The desmosome: cell science lessons from human diseases. J Cell Sci 119:797806

40. Kricheli D, David M, Frusic-Zlotkin M, Goldsmith D, Rabinov M, Sulkes J, Milner Y (2000) The distribution of pemphigus vulgaris-IgG subclasses and their reactivity with desmoglein 3 and 1 in pemphigus patients and their first-degree relatives (see comments). Br J Dermatol 143:337-342

41. Laffitte E, Skaria M, Jaunin F, Tamm K, Saurat JH, Favre B, Borradori L (2001) Autoantibodies to the extracellular and intracellular domain of bullous pemphigoid 180, the putative key autoantigen in bullous pemphigoid, belong predominantly to the IgG1 and IgG4 subclasses. Br J Dermatol 144:760-768

42. Li N, Aoki V, Hans-Filho G, Rivitti EA, Diaz LA (2003) The role of intramolecular epitope spreading in the pathogenesis of endemic pemphigus foliaceus (fogo selvagem). J Exp Med 197:1501-1510

43. Liu Z (2002) Are anti-BP180 IgG1 or IgG4 autoantibodies pathogenic? J Invest Dermatol 119:989-990

44. Liu Z, Diaz LA, Troy JL, Taylor AF, Emery DJ, Fairley JA, Giudice GJ (1993) A passive transfer model of the organ-specific autoimmune disease, bullous pemphigoid, using antibodies generated against the hemidesmosomal antigen, BP180. J Clin Invest 92:2480-2488

45. Mascaro JM Jr, Espana A, Liu Z, Ding X, Swartz SJ, Fairley JA, Diaz LA (1997) Mechanisms of acantholysis in pemphigus vulgaris: role of IgG valence. Clin Immunol Immunopathol 85:90-96

46. Mihai S, Chiriac MT, Herrero-Gonzales JE, Godall M, Jefferies AR, Savage CO, Zillikens D, Sitaru C (2007) Non-complement fixing IgG4 autoantibodies from patients with bullous pemphigoid activate leukocytes and induce dermalepidermal separation. (submitted)

47. Mooney E, Gammon WR (1990) Heavy and light chain isotypes of immunoglobulin in epidermolysis bullosa acquisita. $\mathrm{J}$ Invest Dermatol 95:317-319

48. Morrison LH, Labib RS, Zone JJ, Diaz LA, Anhalt GJ (1988) Herpes gestationis autoantibodies recognize a $180-\mathrm{kDa}$ human epidermal antigen. J Clin Invest 81:2023-2026

49. Ogawa MM, Hashimoto T, Nishikawa T, Castro RM (1989) IgG subclasses of intercellular antibodies in Brazilian pemphigus foliaceus-the relationship to complement fixing capability. Clin Exp Dermatol 14:29-31

50. Ohyama M, Amagai M, Tsunoda K, Ota T, Koyasu S, Hata J, Umezawa A, Nishikawa T (2002) Immunologic and histopathologic characterization of an active disease mouse model for pemphigus vulgaris. J Invest Dermatol 118:199-204

51. Oostingh GJ, Sitaru C, Kromminga A, Lührs H, Zillikens D (2005) Subclass distribution of collagen type VII specific autoantibodies in patients with inflammatory bowel diseases. J Dermatol Sci 37:182-184

52. Parlowsky T, Welzel J, Amagai M, Zillikens D, Wygold T (2003) Neonatal pemphigus vulgaris: IgG4 autoantibodies to desmoglein 3 induce skin blisters in newborns. J Am Acad Dermatol 48:623-625

53. Patton T, Plunkett RW, Beutner EH, Deng JS, Jukic DM (2006) IgG4 as the predominant IgG subclass in pemphigoides gestationis. J Cutan Pathol 33:299-302 
54. Payne AS, Hanakawa Y, Amagai M, Stanley JR (2004) Desmosomes and disease: pemphigus and bullous impetigo. Curr Opin Cell Biol 16:536-543

55. Payne AS, Ishii K, Kacir S, Lin C, Li H, Hanakawa Y, Tsunoda K, Amagai M, Stanley JR, Siegel DL (2005) Genetic and functional characterization of human pemphigus vulgaris monoclonal autoantibodies isolated by phage display. J Clin Invest 115:888-899

56. Ravetch JV, Bolland S (2001) IgG Fc receptors. Annu Rev Immunol 19:275-290

57. Rock B, Martins CR, Theofilopoulos AN, Balderas RS, Anhalt GJ, Labib RS, Futamura S, Rivitti EA, Diaz LA (1989) The pathogenic effect of IgG4 autoantibodies in endemic pemphigus foliaceus (fogo selvagem). N Engl J Med 320:1463-1469

58. Schmidt E, Reimer S, Kruse N, Jainta S, Bröcker EB, Marinkovich MP, Giudice GJ, Zillikens D (2000) Autoantibodies to BP180 associated with bullous pemphigoid release interleukin- 6 and interleukin- 8 from cultured human keratinocytes. J Invest Dermatol 115:842-848

59. Schur PH (1987) IgG subclasses-a review. Ann Allergy 58:89-96, 99

60. Shimanovich I, Mihai S, Oostingh GJ, Ilenchuk TT, Brocker EB, Opdenakker G, Zillikens D, Sitaru C (2004) Granulocyte-derived elastase and gelatinase $\mathrm{B}$ are required for dermal-epidermal separation induced by autoantibodies from patients with epidermolysis bullosa acquisita and bullous pemphigoid. J Pathol 204:519-527

61. Shirakata Y, Shiraishi S, Sayama K, Miki Y (1990) Subclass characteristics of IgG autoantibodies in bullous pemphigoid and pemphigus. J Dermatol 17:661-666

62. Sitaru C, Zillikens D (2005) Mechanisms of blister induction by autoantibodies. Exp Dermatol 14:861-875

63. Sitaru C, Kromminga A, Hashimoto T, Bröcker EB, Zillikens D (2002a) Autoantibodies to type VII collagen mediate Fcgamma-dependent granulocyte activation and induce dermal-epidermal separation in cryosections of human skin. Am J Pathol 161:301-311

64. Sitaru C, Schmidt E, Petermann S, Munteanu SL, Bröcker EB, Zillikens D (2002b) Autoantibodies to bullous pemphigoid antigen 180 induce dermal-epidermal separation in cryosections of human skin. J Invest Dermatol 118:664-671

65. Sitaru C, Powell J, Shimanovich I, Jainta S, Kirtschig G, Wojnarowska F, Zillikens D (2003) Pemphigoid gestationis: maternal sera recognise epitopes restricted to the N-terminal portion of the extracellular domain of BP180 not present on its shed ectodomain. Br J Dermatol 149:420-422

66. Sitaru C, Goebeler M, Zillikens D (2004) Bullöse Autoimmundermatosen (I): Pathogenese und Diagnostik. JDDG 2:123-139

67. Sitaru C, Mihai S, Otto C, Chiriac MT, Haußer I, Dotterweich B, Saito H, Rose C, Ishiko A, Zillikens D (2005) Induction of dermal-epidermal separation in mice by passive transfer of antibodies to type VII collagen. J Clin Invest 115:870-878

68. Sitaru C, Chiriac MT, Mihai S, Büning J, Gebert A, Ishiko A, Zillikens D (2006) Induction of complement-fixing autoantibodies against type VII collagen results in subepidermal blistering in mice. J Immunol 177:3461-3468

69. Skaria M, Jaunin F, Hunziker T, Riou S, Schumann H, Bruckner-Tuderman L, Hertl M, Bernard P, Saurat JH, Favre B, Borradori L (2000) IgG autoantibodies from bullous pemphigoid patients recognize multiple antigenic reactive sites located predominantly within the $\mathrm{B}$ and $\mathrm{C}$ subdomains of the COOH-terminus of BP230. J Invest Dermatol 114:998-1004
70. Soundararajan S, Kikuchi Y, Joseph K, Kaplan AP (2005) Functional assessment of pathogenic IgG subclasses in chronic autoimmune urticaria. J Allergy Clin Immunol 115:815-821

71. Stanley JR, Amagai M (2006) Pemphigus, bullous impetigo, and the staphylococcal scalded-skin syndrome. N Engl J Med 355:1800-1810

72. Suzuki M, Harada S, Yaoita H (1992) Purification of bullous pemphigoid IgG subclasses and their capability for complement fixation. Acta Derm Venereol 72:245-249

73. Suzuki M, Harada S, Owaribe K, Yaoita H (1996) Intracellular ionic changes induced by bullous pemphigoid IgG subclasses. Autoimmunity 23:181-197

74. Suzuki M, Harada S, Yaoita H, Nakagawa H (1999) Bullous pemphigoid $\mathrm{IgG} 2$ and $\mathrm{IgG} 4$ antibodies have a capability to inhibit a transient increase of intracellular $\mathrm{Ca}^{2+}$ induced by bullous pemphigoid IgG1 antibody. Autoimmunity 30:85-91

75. Suzuki M, Murata S, Yaoita H, Nakagawa H (2002) An antibody to $\mathrm{BP} 180 \mathrm{kDa}$ antigen is able to induce an increase of intracellular $\mathrm{Ca}^{2+}$ concentration in DJM-1 (human squamous cell carcinoma) cells. Autoimmunity 35:271-276

76. Tao MH, Smith RI, Morrison SL (1993) Structural features of human immunoglobulin $G$ that determine isotype-specific differences in complement activation. J Exp Med 178:661-667

77. Terry WD, Fahey JL (1964) Subclasses of human gamma-2globulin based on differences in the heavy polypeptide chains. Science 146:400-401

78. Warren SJ, Arteaga LA, Rivitti EA, Aoki V, Hans-Filho G, Qaqish BF, Lin MS, Giudice GJ, Diaz LA (2003) The role of subclass switching in the pathogenesis of endemic pemphigus foliaceus. J Invest Dermatol 120:104-108

79. Wilson CL, Wojnarowska F, Dean D, Pasricha JS (1993) IgG subclasses in pemphigus in Indian and UK populations. Clin Exp Dermatol 18:226-230

80. van de Winkel JG, Capel PJ (1993) Human IgG Fc receptor heterogeneity: molecular aspects and clinical implications. Immunol Today 14:215-221

81. Woodley DT, Ram R, Doostan A, Bandyopadhyay P, Huang Y, Remington J, Hou Y, Keene DR, Liu Z, Chen M (2006) Induction of epidermolysis bullosa acquisita in mice by passive transfer of autoantibodies from patients. J Invest Dermatol 126:1323-1330

82. Woof JM, Burton DR (2004) Human antibody-Fc receptor interactions illuminated by crystal structures. Nat Rev Immunol 4:89-99

83. Yamada H, Hashimoto T, Nishikawa T (1989) IgG subclasses of intercellular and basement membrane zone antibodies: the relationship to the capability of complement fixation. J Invest Dermatol 92:585-587

84. Yamamoto K, Inoue N, Masuda R, Fujimori A, Saito T, Imajoh-Ohmi S, Shinkai H, Sakiyama H (2002) Cloning of hamster type XVII collagen cDNA, and pathogenesis of anti-type XVII collagen antibody and complement in hamster bullous pemphigoid. J Invest Dermatol 118:485-492

85. Yancey KB (2005) The pathophysiology of autoimmune blistering diseases. J Clin Invest 115:825-828

86. Yeh SW, Cavacini LA, Bhol KC, Lin MS, Kumar M, Duval M, Posner MR, Ahmed AR (2006) Pathogenic human monoclonal antibody against desmoglein 3. Clin Immunol 120:6875

87. Zillikens D (1999) Acquired skin disease of hemidesmosomes. J Dermatol Sci 20:134-154

88. Zillikens D, Rose PA, Balding SD, Liu Z, Olague-Marchan M, Diaz LA, Giudice GJ (1997) Tight clustering of extracellular BP180 epitopes recognized by bullous pemphigoid autoantibodies. J Invest Dermatol 109:573-579 